\section{$\S 15$. Prevention of Reversed Flow in Gas Divertor with High Vacuum Chamber}

Kawamura, K., Takayama, K. (Res. Inst. Sci. Tech. Tokai Univ.), Shibuya T. (Dept. Elect. Photo. Opt. Tokai Univ.), Matsubara, A., Tonegawa, A. (Dept. Phys. Sci. Tokai Univ.), Sato, K.

\section{i) Introduction}

A reduction in a reversed flow of gas in a gas divertor toward a main plasma is required to achieve both a low thermal load on a divertor plate and high magnetic confinement in the main plasma.1) It is the purpose of this paper to evaluate experimentally the effect of the high vacuum (HV) chamber set in front of an inlet of the gas divertor on the prevention of the reversed gas flow.

ii) Experimental setup

Fig. 1 shows the TPD-II (Test Plasma generated by Direct Current) at the National Institute of Fusion Science. The helium plasma produced in a plasma source goes out through an experimental and the HV chambers, and contact finally with the $\mathrm{Ne}$ gas in the gas divertor chamber. The diameter of the orifice 2 was $10 \mathrm{~mm}$ comparable to the effective He plasma diameter. The $\mathrm{Ne}$ gas tended to flow into the experimental chamber at neutral gas pressure $\mathrm{P}_{\mathrm{E}}$, of $\sim 0.1 \mathrm{~Pa}$. The neutral gas pressure in the HV chamber, $\mathrm{P}_{\mathrm{HV}}$, was varied from $\sim 0.1 \mathrm{~Pa}$ to $\sim 8 \mathrm{~Pa}$. The reversed $\mathrm{Ne}$ gas flow was detected with a quadrupole mass spectrometer (Q-mass) at the experimental chamber. The variation of reversed $\mathrm{Ne}$ gas flow was determined with both the pressure difference between $\mathrm{P}_{\mathrm{HV}}$ and $\mathrm{P}_{\mathrm{E}}$ and the plasma density $n_{p}$.

iii) Experimental Results

The amount of the reversed $\mathrm{Ne}$ gas flow, Q, is plotted on Fig.2 in the range of the pressure difference between $\mathrm{P}_{\mathrm{HV}}$ and $\mathrm{P}_{\mathrm{E}}, \Delta \mathrm{P}\left(=\mathrm{P}_{\mathrm{HV}}-\mathrm{P}_{\mathrm{E}}\right)$, for various $\mathrm{n}_{\mathrm{p}}$. The slope of $\mathrm{Q}$ against $\Delta \mathrm{P}$ decreases with increasing $n_{\mathrm{p}}$. Such a slope under no plasma may be related to conductance, $\mathrm{C}_{0}$, for the orifice 2 in Fig. 1, defined by

$$
Q_{0}=C_{0} \Delta P,
$$

where $\mathrm{Q}_{0}$ is the amount of reversed $\mathrm{Ne}$ gas flow under no plasma. The dependence of a ratio given by $\mathrm{C} / \mathrm{C}_{0}$ on $\mathrm{n}_{\mathrm{p}}$ is shown in Fig.3. Here, $\mathrm{C}$ represents the conductance under the plasma existence. The ratio of $\mathrm{C} / \mathrm{C}_{0}$ decreases with increasing $\mathrm{n}_{\mathrm{p}}$. It can be considered that the reversed $\mathrm{Ne}$ particles are scattered by collisions with the He plasma; thus,

$$
\frac{d Q(z)}{d z}=-n_{p} \sigma Q(z),
$$

where $\mathrm{Q}(\mathrm{z})$ and $\sigma$ are the amount of reversed Ne flow at axial position $\mathrm{z}$ from the orifice 3 and the cross section of the scattering of $\mathrm{Ne}$ particles. Substituting a distance from the orifice 3 to the orifice $2, \mathrm{~L}(=0.32 \mathrm{~m})$, to $\mathrm{z}$, we obtain

$$
Q=C_{0} \Delta P e^{-\sigma L n_{p}}=C \Delta P,
$$

where $C$ is $C_{0} \exp \left(-L \sigma n_{p}\right)$. The value of $\sigma$ estimated by taking the slope obtained from Fig. 3 and the distance $\mathrm{L}$ is approximately $6 \times 10^{-20} \mathrm{~m}^{2}$, which is comparable to the value of $10^{-19} \mathrm{~m}^{2}$ for the cross section of elastic collision between $\mathrm{Ne}$ and $\mathrm{He}$ ions. The amount of reversed $\mathrm{Ne}$ gas flowing into the experimental chamber will be predicted by using eq.(3).

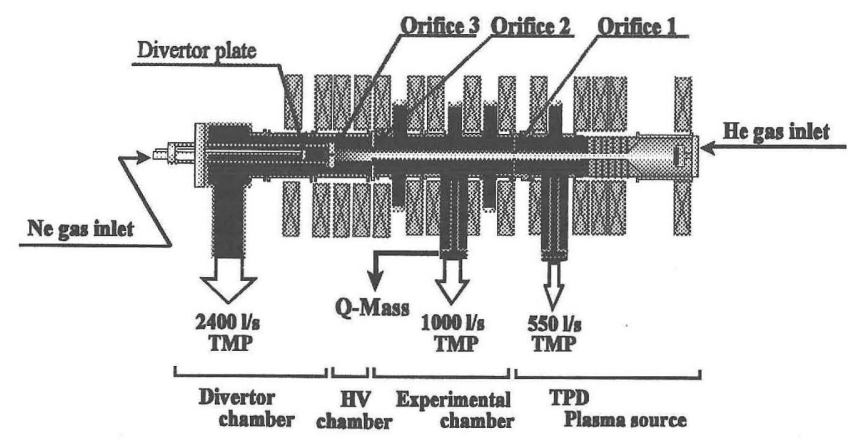

Fig. 1. Schematic diagram of the Test Plasma produced by Direct current II (TPD-II) in the National Institute for Fusion Science. Diameters for the orifices 2, and 3 are $10 \mathrm{~mm}$ and $2 \mathrm{~mm}$, respectively.

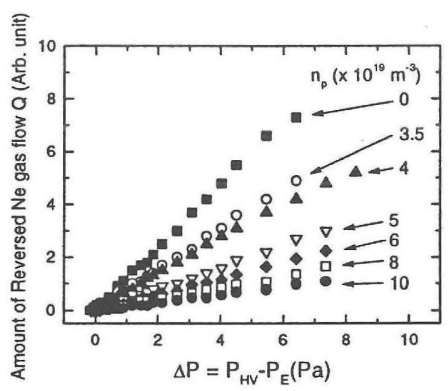

Fig 2. Amount of the reversed neon gas flow, $\mathrm{Q}$, as a function of the pressure difference between $\mathrm{P}_{\mathrm{HV}}$ and $\mathrm{P}_{\mathrm{E}}, \Delta \mathrm{P}$ $\left(=P_{H V}-P_{E}\right)$ for various plasma density $n_{p}$ (numbers in the frame).

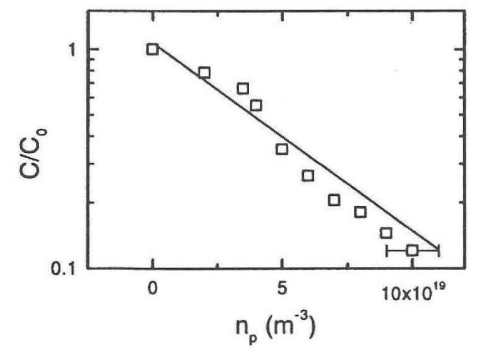

Fig. 3. Dependence of a ratio given by $C / C_{0}$ on the plasma density $\mathrm{n}_{\mathrm{p}}$. The values of $\mathrm{C}$ and $\mathrm{C}_{0}$ are slopes obtained from $\mathrm{Q}$ vs. $\triangle \mathrm{P}$ in Fig.2 under the plasma and no plasma, respectively.

1) Matsubara, A., et al. : J. Nucl. Sci. Tech., Vol. 37, No.6, (2000) 555 . 